\title{
Role of Lower Limb Muscles during Heading of the Ball by Young Professional Soccer Players
}

\author{
MOHAMED Y. BERIKA, M.D. \\ The Department of Rehabilitation Science, College of Applied Medical Sciences, King Saud University, KSA \\ andThe Department of Anatomy, Faculty of Medicine, Mansoura University, Mansoura, Egypt
}

\begin{abstract}
Background: Football is one of the most popular sports worldwide. Heading of the ball is an essential part of the game. There is no much knowledge about the rule of lower limb muscles during the heading of the ball.

Aim of Study: To examine actions of quadriceps, tibialis anterior, hamstrings, and calf muscles during the heading of the ball by using electromyography.

Material and Methods: The actions of quadriceps, tibialis anterior, hamstrings, and calf muscles are studied by electromyography in 15 young professional soccer players from different positions. The players headed the ball forwardly from four different positions: Standing still; jumping; running forward; running and jumping forward.

Results: We found that all examined lower limb muscles were active during the heading of the ball especially the tibialis anterior which produced more significant strength than all other examined muscles in all different positions of the heading of the ball.

Conclusion: This study suggests that healthy well trained lower limb muscles especially the tibialis anterior may be essential for the accurate and effective heading of the ball in professional soccer players. In addition, professional players should avoid heading of the ball when lower limb muscles are injured especially tibialis anterior.
\end{abstract}

Key Words: Soccer-Heading - Lower limb muscles.

\section{Introduction}

PRACTICING the sport of soccer is growing rapidly around the world. Approximately, 120 million players are registered worldwide [1]. According to the International Federation of Association Football (FIFA), this number is increased to 240 million in 2001 and it is expected to be more than that in 2020. In the united states, 3 million youth players are officially registered [2]. It is

Correspondence to: Dr. Mohamed Y.

Berika,E-Mail: mberika@ksu.edu.sa widely considered to be the most popular sport in the world. In contrast to most other sports, soccer uses the head as a means of advancing and passing the ball, and scoring goals.

Heading of the ball is essential for all football players even gall keepers. The accuracy and coordination of heading in professional soccer players of different positions and found that there was not a significant statistical difference between defenders, midfielders, and forwards [3].

Lower limbs are used mainly in acceleration and deceleration in a soccer game [4]. The activity of lower limb muscles is also required during the heading of the ball. There is a lack of knowledge regarding different rules of lower limb muscles during the heading of the ball. This study aims to evaluate the use of different groups of lower limb muscles during the heading of the ball by electromyographic data for fifteen young soccer players.

\section{Material and Methods}

The ball was thrown to fifteen young male soccer players (between eleven and twelve years old) from the right side. The players headed the ball forwardly from four different positions: Standing still; jumping; running forward; running and jumping forward. This study was conducted in Mansoura Sporting Club between 2018-2019.

Electromyographic data for four lower-limb muscles were sampled while the subjects were heading the ball and were filmed. Muscle activity was collected simultaneously from the mid-bellies of quadriceps, tibialis anterior, gastrocnemius, and hamstrings muscles in both lower limbs using eight surface electrodes (DE-2.3 silver surface EMG electrodes, Single Differential, dimensions $41 \mathrm{X}$ 
20 X 5mm, noise 1.2uV (RMS, R.T.I.), Delsys Inc., Boston, MA) and recorded on an EMG Myomonitor IV Wireless Transmission \& Datalogging System (Delsys Inc, Boston, MA), with real-time EMG viewing on a laptop computer. As a wireless transmitter, the Myomonitor sends EMG data over a Wireless Local Area Network (WLAN) to the host computer for real-time display and storage utilizing EmgCE software (Delsys Inc., Boston, MA). The raw EMG signal was converted to a Root Mean Square (RMS) at each 0.0625-second interval during the heading of the ball in all men- tioned positions, recording using EMGWorks, ( Delsys Inc., Boston, MA).

\section{Results}

This study included fifteen youth male soccer players who regularly performed headers and played predominately on upper-skill level team, the mean age was $11.6(11-12 \pm 0.41)$.

The mean strength was calculated for each muscle separately in each position as shown in the next tables (Tables 1,4).

Table (1): The mean strength (root square meter) of the muscle during heading the ball from the standing position.

\begin{tabular}{lcccccccc}
\hline Muscle & Quadriceps & Hamstring & $\begin{array}{c}\text { Tibialis } \\
\text { anterior }\end{array}$ & $\begin{array}{c}\text { Calf } \\
\text { muscles }\end{array}$ & Quadriceps & Hamstring & $\begin{array}{c}\text { Tibialis } \\
\text { anterior }\end{array}$ & $\begin{array}{c}\text { Calf } \\
\text { muscles }\end{array}$ \\
\hline Side & Right & Right & Right & Right & Left & Left & Left & Left \\
Mean & 34.11 & 42.9 & 43.7 & 21.6 & 36.09 & 26.4 & 46.8 & 26.1 \\
Minimum & 21.7 & 25.9 & 27.3 & 15.68 & 20.4 & 12.2 & 20.57 & 14.2 \\
Maximum & 49.5 & 74.8 & 60.2 & 30.5 & 13.8 & 46.6 & 107.2 & 33.2 \\
St. deviation & 11.6 & 17.6 & 17.4 & 5.7 & 61.26 & 11.5 & 33.3 & 7.1 \\
\hline
\end{tabular}

Table (2): The mean strength (root square meter) of the muscle during heading the ball from the jumping position.

\begin{tabular}{llllllllll}
\hline Muscle & Quadriceps & Hamstring & $\begin{array}{c}\text { Tibialis } \\
\text { anterior }\end{array}$ & $\begin{array}{c}\text { Calf } \\
\text { muscles }\end{array}$ & Quadriceps & Hamstring & $\begin{array}{c}\text { Tibialis } \\
\text { anterior }\end{array}$ & $\begin{array}{c}\text { Calf } \\
\text { muscles }\end{array}$ \\
\hline Side & Right & Right & Right & Right & Left & Left & Left & Left \\
Mean & 42.6 & 53.1 & 193.4 & 28.5 & 224.8 & 39.2 & 55.7 & 36.8 \\
Minimum & 34.17 & 35.9 & 18.5 & 11.5 & 40 & 24.6 & 18.2 & 19.9 \\
Maximum & 52.3 & 72.5 & 796.1 & 40.8 & 951.9 & 55.3 & 92.4 & 59.2 \\
St. deviation & 6.1 & 12.5 & 312.2 & 11.7 & 376.3 & 39.2 & 28 & 16.9 \\
\hline
\end{tabular}

Table (3): The mean strength (root square meter) of the muscle during heading the ball from the running position.

\begin{tabular}{llllllllll}
\hline Muscle & Quadriceps & Hamstring & $\begin{array}{c}\text { Tibialis } \\
\text { anterior }\end{array}$ & $\begin{array}{c}\text { Calf } \\
\text { muscles }\end{array}$ & Quadriceps & Hamstring & $\begin{array}{c}\text { Tibialis } \\
\text { anterior }\end{array}$ & $\begin{array}{c}\text { Calf } \\
\text { muscles }\end{array}$ \\
\hline Side & Right & Right & Right & Right & Left & Left & Left & Left \\
Mean & 50.4 & 51.8 & 42.6 & 37.8 & 52.9 & 33.8 & 230 & 35.1 \\
Minimum & 34.5 & 28 & 16.35 & 24 & 35.9 & 16 & 27.9 & 19.8 \\
Maximum & 80.02 & 68.4 & 73.93 & 61.3 & 85.4 & 67.3 & 1000 & 48.1 \\
St. deviation & 16.2 & 15 & 20.8 & 13.8 & 19.3 & 18.6 & 230 & 9.4 \\
\hline
\end{tabular}

Table (4): The mean strength (root square meter) of the muscle during heading the ball from the jumping from running position.

\begin{tabular}{lcccccccc}
\hline Muscle & Quadriceps & Hamstring & $\begin{array}{c}\text { Tibialis } \\
\text { anterior }\end{array}$ & $\begin{array}{c}\text { Calf } \\
\text { muscles }\end{array}$ & Quadriceps & Hamstring & $\begin{array}{c}\text { Tibialis } \\
\text { anterior }\end{array}$ & $\begin{array}{c}\text { Calf } \\
\text { muscles }\end{array}$ \\
\hline Side & Right & Right & Right & Right & Left & Left & Left & Left \\
Mean & 51.3 & 54.1 & 51.5 & 36.7 & 52.9 & 51.2 & 240 & 202 \\
Minimum & 23.5 & 37.8 & 26.7 & 25.9 & 43.1 & 31 & 38.8 & 29.3 \\
Maximum & 98.4 & 68.8 & 103.5 & 52.8 & 74.1 & 108 & 1000 & 875 \\
St. deviation & 26.1 & 12 & 28.1 & 10.8 & 11.7 & 30 & 393.4 & 348.2 \\
\hline
\end{tabular}


The mean strength of quadriceps muscles in all test positions were 86.1 (13.8-951.1 \pm 143.1$)$, hamstrings $44.1(12.2-108.8 \pm 19.2)$, tibialis anterior 110 (16.3-1000 \pm 237.4$)$, and for calf muscles was 53.1 (11.5-875.1 \pm 132$)$. Despite of the significant higher strength of the left calf muscles than the right ones $(p=0.001)$, there was no statistically significant difference in the muscle strength comparing corresponding other muscles of each side in each position separately.

Tibialis anterior muscles in all positions showed the highest strength which was statistically significant ( $p=0.04,0.003$, and 0.024) compared to quadriceps hamstrings and calf muscles respectively Fig. (1).

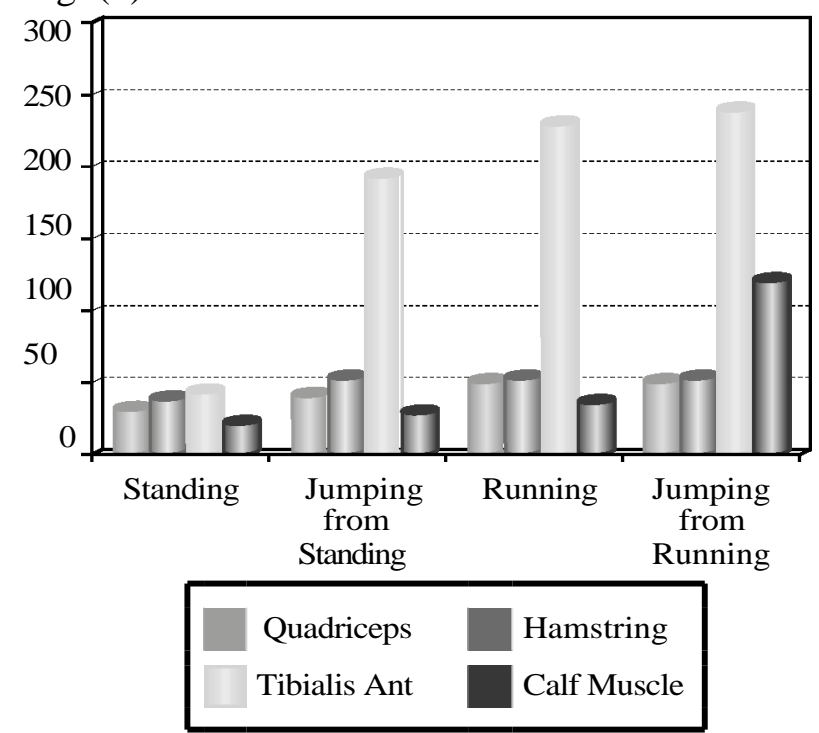

Fig. (1): Muscle strength during each position: Tibialis anterior muscles show the higher strength among all the muscles studied.

\section{Discussion}

This study used measurement of EMG activity as a surrogate for measurement of lower limbs muscles strength during heading of the ball in fifteen young soccer players. Electromyography ( EMG) is often used to study the anatomy and physiology of movement [5-7].

EMG activity was recorded from quadriceps, hamstring's, tibialis anterior, and calf muscles during the heading of the ball from standing, jumping, running, and jumping positions.

Heading of the ball from all positions was associated with statistically significant increased EMG activity in all studied lower limb muscles.

Although muscle strength of the left side muscles appeared higher than the corresponding mus cles of the right side, there was no statistically significant difference between muscle strength of both sides.

One of the major roles of lower limb muscles is to keep the center of gravity of the body which passes just behind the hip joint and in front of the knee and ankle joints during standing. The studied muscles tended to keep that center during the heading of the ball to keep the body balanced.

During heading the ball from a standing position the quadriceps contracts to keep the knee joint extended. This is associated with hamstrings activity to keep the lower limb standing as a rigid pillar.

Tibialis anterior muscles (right and left) produced higher strength than other studied lower limb muscles in all positions. This may be to prevent falling backward during posterior backswing just before heading off the ball. Calf muscles produced less activity than other studied lower limb muscles. This may help to keep the stability of the ankle joint.

The data collected from the EMG sensors used in this study revealed an interesting finding that tibialis anterior muscles produced statistically significant higher strength than quadriceps, hamstring, and calf muscles during all studied lower limb positions during heading of the ball.

It was found that a $68 \%$ decrease in effective mechanical advantage of knee extensor (quadriceps) when humans changed gait from a walk to a run compared with a $23 \%$ increase in effective mechanical advantage of the ankle extensor tibialis anterior [ 8]. This implies that the tibialis anterior has an important role in stabilizing the ankle and keeping the balance of the body during complicated lower limb activities. It was concluded that the central nervous system deals with movements produced by lower limbs to serve the stabilization of the spine [9].

Trainers and coaches should give more attention to lower limb muscles to talented kids in heading of the ball especially ankle extensors as tibialis anterior specific training programs to improve heading ability in the training schedule of soccer players at a professional level.

Lower limb injuries may affect the accuracy of the heading of the ball or lead to a faulty heading of the ball which may be harmful. Many studies have focused attention on the potential for longterm cognitive deficits caused by faulty heading [1,10-12]. 
This study suggests that the integrity of the lower limb muscles is essential for the heading of the ball in soccer sport especially the tibialis anterior. Proper coordination of the lower-limb muscles, particularly the tibialis anterior appears to be necessary during the heading of the ball which is mediated by the central nervous system.

The affection of the tibialis anterior muscle even by fatigue causes abnormal movement of the lower limb which will affect the heading of the ball. The effect of tibialis anterior fatigue on ankle dorsiflexion angle and tibial axial acceleration was studied. It was found that fatigued tibialis anterior caused the ankle joint to become less stiff, thereby increasing the lower extremity attenuation [13].

This study suggests that healthy, strong, coordinated well trained lower limb muscles especially the tibialis anterior may be essential for the accurate and effective heading of the ball in professional soccer players. Furthermore, players should avoid heading of the ball when their lower limb muscles are injured especially the tibialis anterior. This should be considered by soccer coaches and trainers for the safety and effectiveness of the game and the players.

\section{References}

1- JORDAN S.E., GREEN G.A., GALANTY H.L., MANDELBAUM B.R. and JABOUR B.A.: Acute and chronic brain injury in United States national team soccer players. American Journal of Sports Medicine, 24920: 205-10, 1996.

2- O'KANE J.W.: Is Heading in Youth Soccer Dangerous Play? Phys. Sportsmed., 44 (2): 190-4, 2006.

3- ERKMEN N.: Evaluating the heading in professional soccer players by playing positions. Journal of Strength and Conditioning Research, 23: 6. 1723-8, 2009.
4- OLIVA-LOZANO J.M., FORTIS V., KRUSTRUP P. and MUYOR J.M.: Acceleration and sprint profiles of professional male football players in relation to playing position. PloS One, Aug. 6, 15 (8): e0236959, 2020.

5- BORRANI F., CANDAU R., MILLET G.Y., PERREY S. , FUCHSLOCHER J. and ROUILLON J.D.: Is the VO2 slow component dependent on progressive recruitment of fast-twitch fibers in trained runners? Journal of Appllied Physiology, 90: 2212-20, 2001.

6- HANON C., THEPAUT-MATHIEU C. and VANDEWALLE H.: Determination of muscular fatigue in elite runners. European Journal of Applied Physiology, 94: 118-25, 2005.

7- SMOLIGA J.M., MYERS J.B., REDFERN M. and LEPHART S.M.: Reliability and precision of EMG in leg, torso, and arm muscles during running. Journal of Electromyography and Kinesiology, 20: e1-e9, 2010.

8- BIEWENER A.A., FARLEY T.C., ROBERTS J.T. and TEMANER M.: Muscle mechanical advantage of human walking and running: Implications for energy cost. Journal of Applied Physiology, 97: 2266-74, 2004.

9- HODGES P.W. and RICHARDSON C.A.: Contraction of the abdominal muscles associated with movement of the lower limb. Physical Therapy, 77: 2 (February), 1997.

10- TYSVAER A.T., STORLI O.V. and BACHEN N.I.: Soccer injuries to the brain: a neurologic and electroencephalographic study of former players. Acta Neurol. Scand., 80: 151-6, 1989.

11- MATSER E.J.T., KESSELS, A.G. LEZAK, M.D. JORDAN and B.D. TROOST. J.: Neuropsychological impairment in amateur soccer players. JAMA, 282: 971-3, 1999.

12- DAIZ-RODRIGEZ Y.I. and SALVATORE A.P.: Impacts of Sports-Related Subconcussive Injuries in Soccer Players. Semin Speech Lang. Feb., 40 (1): 57-64, 2019.

13- DUQUETTE A.M. and ANDREWS D.M.: Tibialis anterior muscle fatigue leads to changes in tibial axial acceleration after impact when ankle dorsiflexion angles are visually controlled. Human Movement Science, 29: 4, August, 567-77, 2010. 


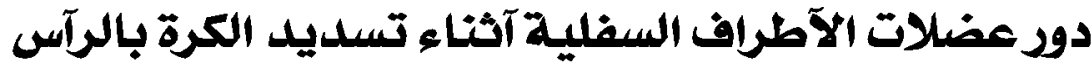

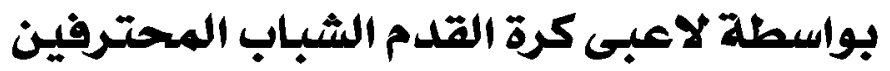

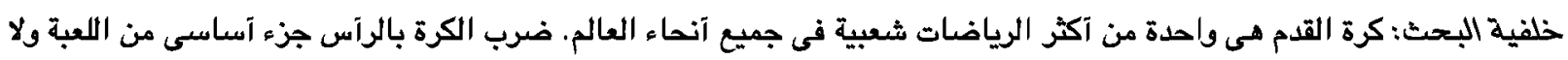

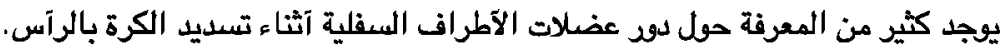

الهدف من الدراسة: فحص آفعال العضلة الآمامية رياعية الرئوس، عضلات الفخذ الخلفية، الظنبوب الآمامية، وعضلة الساق الخلفية آثناء تسديد الكرة بالرآس بإستخدام التخطيط الكهربى اللعضلات.

المواد والآسـاليب: تمت دراسة حركات العضلة الامامية رياعية الرؤوس، عضلات الفخذ الخلفية، الظنبوب الآمامية، وعضلة الساق الخلفية

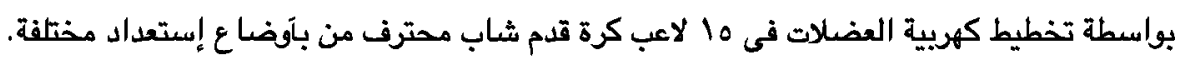

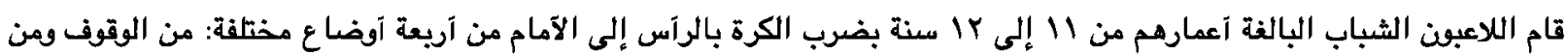
القفز ومن الجرى إلى الآمام ومن الجرى إلى الآمام ثم العمار القفز.

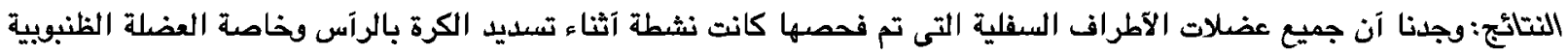

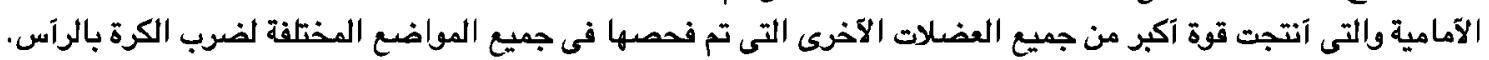

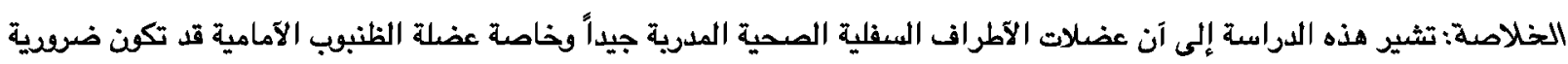

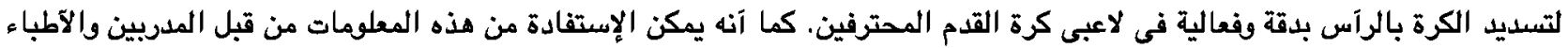

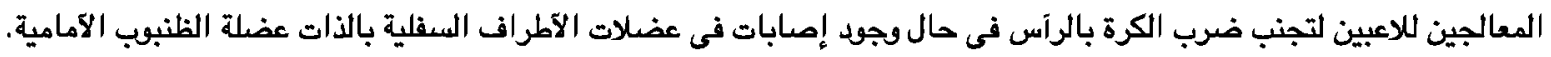

